\title{
La abuela autómata. Mecánica y androides en el siglo de las luces*
}

Jaime Herrero Sánchez

Se presentaba hace poco tiempo en el Círculo de Bellas Artes de Madrid, coincidiendo con la Feria Internacional de Arte (ARCO), una representación-instalación, o «performance», de Matt Heckert, y por esos mismos días también la «Madre metálica» de Tigram, un androide o robot humanoide.

En el evento, varias figuras metálicas representando dragones y variados híbridos de autómatas se agitaban frenéticamente, escupían fuego y cascadas de chispas, poniendo en peligro con sus aspavientos y contorsiones al sorprendido público. Sorprendido en los dos sentidos de asustado y perplejo. Perplejo sobre todo por la crítica de arte, que presentaba el espectáculo como una novedad y a sus instaladores por inventores de un espectáculo y un género nuevos, que alguno tuvo el valor de llamar Teatro mecánico-eléctrico. Me desasosegaba especialmente la «Máquina de andar y picotear» como algo ya visto, hasta que rastreando en la oscuridad del Siglo de las Luces recordé el célebre «Pato» de Vaucanson, su hermano gemelo en el tiempo. ¿Quién le había transmitido los genes metálicos?

Otra figura me inquietaba asimismo, esa Madre Metálica de Tigram que no acababa de asumir como la Eva del Edén postindustrial. Ciertamente, porque esta madre es solo un eslabón en la cadena de criaturas que van haciéndose un espacio entre sus modelos humanos y, como en toda buena familia, tienen

\footnotetext{
* Este texto, ligeramente adaptado a las convenciones de la publicación, fue expuesto en el Curso de Verano «Artes y culturas populares en el siglo XVIII», celebrado en Llanes (Asturias), del 12 al 19 de julio de 1999, organizado por el IFES XVIII.
}

Cuadernos de Estudios del Siglo XVIII, núms. 8 y 9. Oviedo, Instituto Feijoo de Estudios del Siglo XVIII, Universidad de Oviedo, 1999, págs. 171-180. 
una abuela común que con paciencia podemos seguir hasta los salones y talleres de la Ilustración.

Aún antes del xVIII, la cacharrería animada de juguetes de resorte, relojería con autómatas giróvagos y complicados artilugios musicales, había poblado las cortes de los siglos XVI y XVII, como diversión, maravilla y objetos testigo de los cambios de mentalidad del hombre acerca de sí mismo, la ciencia y la naturaleza y la relación entre ellos ${ }^{1}$. Relación que se podía colegir por las marcas o señales impresas en su exterior, las «signaturas» o simpatía o antipatía de las unas por las otras.

El hombre formaba parte de una «Armonía universal», un orden superior del que participan los planetas y las constelaciones, las criaturas naturales y entre ellas el hombre, y en él el cuerpo y el alma. Nos lo dice Lope en la Arcadia:

Están todas las cosas naturales

ligadas en cadena de armonía,

los elementos y orbes celestiales,

aunque contrarios, en igual porfía.

Una inmensa esfera en cuyo armónico girar, todas las cosas del macro y microcosmos son un espejo y el reflejo de las demás. El centro de este carrusel es, por supuesto, el Supremo Relojero.

Estamos en el territorio de la retórica y del pensamiento especulativo. Así nos llega el viejo pensamiento medieval, renacentista y barroco, a las playas del XVII, en los discursos que relacionan aún estética y razón, arte y ciencia, en las retóricas de la ilusión, y comienzan a convivir tres tradiciones de acercamiento a la realidad. Una corriente «organicista» de relaciones biológicas, y no me apuraría en apuntar que visuales, de las cosas entre sí, con el hombre y con el todo; la tradición «mágica y mística» de armonías celestiales, la influencia del número como cifra y clave del mundo y laberintos esotéricos del Centro, en los que el centro supone un arcano distinto para cada filósofo-jardinero; la «mecanicista», que combina las analogías y simpatías de los sentidos por analogías mecánicas y matemáticas.

El medio en el que Descartes desenvuelve su primera actividad es aún el pensamiento mágico-especulativo de los fantasmas de la realidad, a lo que posiblemente colabora su adscripción a la secta de la Rosacruz, si esto es cierto y si lo es también lo poco que adivinamos a través de la espesa capa de misterio

\footnotetext{
${ }^{1}$ Alfredo Aracil, Juego y artificio. Autómatas y otras ficciones en la cultura del Renacimiento a la Ilustración, Madrid, Cátedra, 1998, p.13. En esta obra fundamental el lector podrá encontrar informaciones más detalladas sobre diversos aspectos aquí comentados.
} 
de los rosacruces, pues como él nos movemos todavía en un mundo de apariencias y no en vano se le ha denominado el «filósofo enmascarado», que guarda de la censura de la época las últimas razones y postulados de su pensamiento.

Pronto va a desarrollar una nueva relación arte-ciencia-naturaleza impregnada de la nueva sensibilidad neoclásica y apoyada en un método cuyo primer enunciado alumbra una antropología filosófica en la que el hombre forma parte de una naturaleza cuya ordenación es fundamentalmente matemática.

Los sentidos son estudiados como las herramientas más idóneas para el conocimiento de lo natural, y muy especialmente la música, cuyas construcciones armónicas y matemáticas mimarían la estructura de la realidad y convierten el arte entonces, no en un símbolo ni alegoría de un universo pensado, sino en una maqueta operable, en un «modelo» en el sentido moderno en que entendemos la mecánica de modelos.

El hombre no está dirigido por el girar de las estrellas, las conjunciones de los astros y la narrativa estética, y ya no hay una Proporción Áurea que lo enmarque; para Descartes, el hombre es sencillamente una máquina, quizás mejor dicho como una máquina y el androide, el autómata antropomorfo, la maqueta, o el modelo más útil, de un universo objetivo. Lo expresa así en el Tratado del hombre: «Supongo que el hombre no es otra cosa que una máquina, o estatua de tierra... Dispone en su interior de todas las piezas requeridas para que el cuerpo se mueva, coma, respire y realice las funciones que le son propias... Conocemos relojes, fuentes artificiales, molinos y otras máquinas similares que habiendo sido realizadas por el hombre, sin embargo, poseen fuerza para moverse de modos distintos en virtud de sus propios medios».

Parece ser que Descartes mismo tenía varios autómatas, uno de ellos, una muñeca llamada Francine, sustituía a una hija ausente. Durante un largo viaje el capitán descubrió en la sentina del barco el cajón de la autómata y la tripulación asustada lo tiró al mar, siendo probablemente el primer entierro marino de autómatas que se conoce.

Las criaturas entran chirriantes y metálicas en el siglo xVIII como una especie de máquinas, y el androide a su vez lo pasea como hombre, o por lo menos un autómata humanoide, o modelo operativo, cuyo creador no esta en el centro de la música de las esferas sino en un taller de la esquina.

Este autómata, que va a habitar el Siglo de las Luces como vecino de excepción, no es aún humano en el estricto sentido del término; no lo habita el espíritu ni trata de imitar la vida, sino de mimar alguna de sus acciones aisladas, poniendo a contribución los recursos cada día más afinados de la micromecánica, cuyas sutiles herramientas vemos muy bien representadas en los grabados de oficios y artesanías de la Enciclopedia francesa. 
Todavía son «sublimes juguetes», pero van abandonando sus actuaciones de corte, diversiones de salón y objetos de «colecciones de maravillas», como músicos articulados de cámara o gentiles pastorcillas; y al paso del siglo adquieren la seriedad, los modales y la estructura del androide, o sea, el hombremáquina, que esa Enciclopedia ilustrada, en los dos sentidos del término, cuenta como «Autómata con figura humana, que por medio de determinados mecanismos adecuadamente dispuestos, actúa y hace otras funciones exteriormente semejantes a las del hombre».

El más destacado de los prodigios fue sin duda el pato de Vaucanson que me trajo a la memoria ese descendiente suyo de Heckert. Éste, sin duda mucho más elaborado, «era capaz de batir las alas, zambullirse en el agua y nadar, tragar grano e incluso expeler un producto parecido al excremento». De este pato original se hicieron innumerables reproducciones de las que nos ha llegado algún resto deteriorado por el que podemos admirar todavía la perfección de la tecnología empleada «utilizando engranajes, muelles, resortes, palancas y levas» de tal complejidad que una de sus alas, por ejemplo se componía de unas 2.000 piezas.

Además del famoso pato, Vaucanson, construye también «El tamborilero», que interpreta «una veintena de aires, minuetos, rigodones y contradanzas», por gracia de la perfecta articulación de las manos y un curioso artilugio pectoral que expele el aire de forma adecuada a las notas de la pequeña flauta.

Otro flautista solitario, sentado en una roca, estaba dotado de un mecanismo encerrado en el pecho que le permitía dosificar el aire preciso para los distintos sones del instrumento.

Uno de estos flautistas, bastante bien conservado, lo encuentra Rafael Sánchez-Mazas, hacia 1935, en el castillo de Boadilla del Monte. Nos dice que «era el sobreviviente del de Viena, el último de los seis ejemplares —uno de ellos de María Antonieta- que se hicieron en vida del autor o una reproducción tardía, pero exacta. La escultura, si, era peor que los originales conocidos. Pero, desde luego, había movido siete dedos sobre los agujeros de la flauta y había disfrutado de tres posiciones de la boca, de tres intensidades de soplo sobre los nueve fuelles y artilugios con pesas de diverso grosor. Para él se inventaron, el primer rodillo de música, todavía de leño con puntas de metal, el tornillo sin fin (que Sánchez-Mazas ignora que ya existía) y las ruedas de transmisión poligonales» ${ }^{2}$.

Jacques de Vaucanson era realmente un ingeniero textil que colaboró eficazmente en los avances de esta industria y además un reformador ilustrado,

${ }^{2}$ Rafael Sánchez-MaZas, Las aguas de Arbeloa y otras cuestiones, Madrid, 1983, pp. 244-245. 
admirado por Voltaire y saludado por la Encyclopédie, que lo recibe como un precursor cuyas invenciones pertenecen más al futuro que al presente.

Estos artilugios compendian los avances de la relojería de la época, piezas de asombrosa perfección como los relojes de Lyon y Cambrai, los de Estrasburgo y españoles, y las joyas de los artesanos rusos, animados por innumerables autómatas musicales. Recordemos el reloj de Jaquet-Droz, del palacio de Villaviciosa de Odón, coronado por un pastor tocando el caramillo, rodeado de perros que ladran, ovejas que balan, pájaros que cantan, cupidos que se balancean, mientras una dama escucha marcando el compás, las melodías que a cada hora toca el pastor.

Otro flautista cazador fue el de Esteban del Espinoy, ingeniero hidráulico que lo diseñó para el infante don Luis hacia 1763. Este melódico cazador de tamaño natural tocaba en su flauta travesera tres tocatas diferentes, que se mudaban a discreción por el movimiento natural de sus dedos, los golpes de lengua, aumentando y disminuyendo el aire de la boca. A su alrededor se mueve, da sus sonidos y se agita un nutrido grupo de figuras animales y vegetales al gusto de la época.

Hacia 1783 el abate Mical presenta en sociedad, en Viena, sus dos «Cabezas parlantes» que, ante el asombro de los espectadores, mantenían este diálogo:

1. ${ }^{a}$ Cabeza. «Le Roi donne la Paix à l'Europe»

2. ' Cabeza. «La Paix couronne le Roi de gloire»

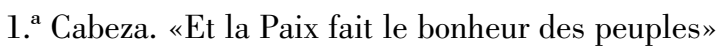

2. ' Cabeza. «O Roi adorable, Père de vos peuples, leur bonheur fait à L'Europe la gloire de vôtre trône» ${ }^{3}$.

Los ilustres físicos Lavoisier y La Place se extasían ante sus vocecitas de fuelle.

Estos artificios andróginos que ocupaban un lugar de excepción en el juego y la especulación de las veladas de la Ilustración, compartían protagonismo con otras invenciones bautismales, las «Vues d'optique», o «cartoline» como se las conoció en España. Eran tarjetas dibujadas a mano, grabadas o impresas más tarde, venían de la estampería popular y eran sencillamente eso, estampas amañadas para ser visualizadas por medio de un aparato óptico que en su versión más simple consistía en una o más lentes fijadas sobre una caja con su pedestal, provista de un espejo de inclinación variable. Las «cartoline», o tarjetitas, representaban vistas de ciudades, escenas de Corte o populares, personajes famo-

\footnotetext{
${ }^{3}$ Apud A. Aracil, op. cit. p. 371.
} 
sos y escenas morales como la frecuentemente reproducida, «El castigo de los cornudos voluntarios».

Estas tarjetas presentaban unos cortes e incisiones con otros dibujos en transparencia, que cobraban vida al ser iluminadas con un punto de luz, y así la escena cambiaba del día a la noche o reproducía la luminaria de un incendio o unos fuegos de artificio. Editadas al principio en costosas ediciones para gabinetes de corte o salones de las familias burguesas, se popularizan enseguida adaptándolas a la nueva diversificación social y a los gustos dominantes de los sectores que acceden a lo que pudiéramos llamar incipiente economía de mercado. Bajan a la calle y recorren los caminos de apartados lugares en exhibición ambulante.

Estos buhoneros de la «legua» complementaban la exhibición con comentarios y explicaciones al gusto y entendederas de su clientela rural y de pequeñas villas y poblaciones; un universo ciego sin más imágenes que las sagradas, o las fugazmente entrevistas en las casas de los señores, si los hubiese.

Versarían sus discursos, tema de las «cartoline», sobre personajes y sucesos políticos y sociales de la época, erigiéndose en portavoces y prensa popular ilustrada; una ventana, sobre aquella realidad más amplia y ajena que la del inmóvil mundo circular cotidiano, que debieron combinar con otras iconografías y discursos de hagiografías y lecciones morales, (avisos del recelo con que el elemento clerical vería este tipo de espectáculos), que venían a trastornar el orden y las categorías del pensamiento de un público al que la Iglesia daba, hasta ese momento forma y contenido.

Conocemos algunas «cartoline» con vistas de monumentos españoles pero fabricadas fuera, pues parece ser que aquí o no se compusieron o no nos ha llegado ninguna muestra.

Las «Vues d'optique» que causan «sorpresa e stupore» con sus primeros y sencillos «efectos especiales», provocan cambios en las costumbres de un público que estaba asumiendo su nueva dimensión cualitativa y cuantitativa en el curso del XVIII, y están en el centro de una reflexión sobre el cambio de la visión colectiva que irá madurando al paso de la sofisticación de sus tecnologías, de la vela y el gas a la electricidad, de la linterna mágica al proyector de diapositivas, del kinetoscopio al cine, la televisión y los multimedia envolventes de la realidad virtual.

Pero volvamos a nuestros humanoides. El autómata que podemos considerar como un verdadero androide es «El escribano» de Knauss, conservado en Viena, y que por un mecanismo alojado en una esfera próxima podía escribir textos complejos y mover la cabeza, mientras los ojos seguían la línea de escritura como si leyese. 
No falta la picaresca, deliciosa compañera del progreso, de la mano del barón transilvano Wolfgang von Kempelen, superintendente de la emperatriz María Teresa de Austria, filósofo y científico ilustrado, que fue encargado del proyecto de reconstrucción del antiguo convento de los Carmelitas en la colina de Buda para teatro del castillo. Allí mismo construyó, en alguno de los talleres de la calle Del Oro o de Los Alquimistas, el celebre «Jugador de ajedrez», de larga vida literaria, con el que recorrió diversas cortes europeas. Compuesto por una especie de caja con un tablero de juego en el que un autómata, vestido de turco, jugaba contra rivales humanos a los que ganaba siempre, y según un comentario de la época «parece seguro que un experto jugador se ocultaba en la caja ${ }^{4}$ ¿Pero si no hubiera sido así?

Por su parte los Droz, padre e hijo, superan toda la cacharrería articulada de Vaucanson y Knauss con los tres autómatas que construyen, cómo no, en Suiza, patria del reloj de cuco y la «mecánica cronológica».

El primero, «El escribano», un chico descalzo de tamaño natural sentado ante un pupitre, que podía mojar la pluma en su tintero y, agitando los ricitos de estopa empolvada, la sacudía dos veces y escribía un texto programado, empleando hasta cuarenta signos o letras. Incluso cambiaba de línea cuando llegaba al final del renglón. Los ojos del autómata seguían los movimientos de la pluma, ofreciendo una asombrosa apariencia de vida. Entre las frases del repertorio del Escriba estaba el axioma de Descartes «Pienso, luego existo».

El «Dibujante» que hacía los retratos de Luis XVI y los reyes de Inglaterra, Jorge III y Carlota, y la «Musicienne», una muchachita circunspecta y algo antipática, que gracias a sus brazos y manos, compleja y sutilmente articulados, interpretaba al clave y órgano variados aires, mientras el pecho se agitaba al compás de la respiración. Al finalizar con un mohín hacía la reverencia.

El éxito de este circo de fantoches mecánicos o "gabinete de maravillas», es tal, que recorre Europa hasta que en 1789, año de la toma de la Bastilla, lo encontramos en Madrid donde lo adquieren los hermanos Gendre, banqueros franceses residentes en la corte, por unas 50.000 liras francesas, suma muy importante para la época, esperando sacar buenos beneficios con su exhibición, cuando la Revolución Francesa y la invasión interrumpen bruscamente el negocio. Los soldados de Napoleón los llevan a París y van a parar al Musée des Illusions, una especie de circo tecnológico, que los exhibe por varias capitales, hasta su descanso definitivo en el Museo de Arte e Historia de Neuchâtel, donde aún pueden contemplarse en una vitrina blindada.

${ }^{4}$ Diario de Madrid, 7 y 9 de abril, 1791. 
Parece ser que los Droz tuvieron aquí problemas con la Inquisición, quizás como el mismo Casanova, que soluciona la buena voluntad de Carlos IV.

La saga de «Ingeniosas invenciones» continuará con los Maillard, más dados a lo maravilloso con sus magos, animales fantásticos y fantasmagorías. En 1778, Wolfgang von Kempelen, idea la «Máquina parlante». No estamos ya ante un autómata en el sentido estricto, sino ante un instrumento práctico reproductor de la voz humana, compuesto por «una caja de resonancia rectangular unida a dos tubos que forman la glotis. Mientras un fuelle envía el aire, los tubos modulan los sonidos, dos válvulas lo apagan o aclaran, y un pabellón circular adosado lo amplifica». Podía según Kempelen pronunciar varios centenares de palabras latinas, francesas e italianas clara y diferenciadamente.

Según Alfredo Aracil, cuyos pasos sigo con gran placer y aprovechamiento por este museo cronológico-mecánico, «nos encontramos ante un pensamiento materialista y mecanicista justo en las antípodas del sentido espiritual y simbólico que habían adquirido las máquinas en la cultura manierista. Ahora la máquina no es reflejo de nada, sino pura y simplemente de sí misma y de su mecanismo; a lo sumo, imagen de un hombre al que la ilustración más radical había desprovisto de alma, un hombre parangonable al perfecto y frío mecanismo de un reloj» ${ }^{5}$. Hemos cerrado el círculo, y estamos de nuevo ante el puro pensamiento cartesiano.

El nuevo estrato burgués, que comienza a gustar de la vulgarización de las ideas, puede acceder a las colecciones de los «Gabinetes de maravillas» y los jardines botánicos que se abren al público, mientras Carlos III funda el Gabinete de Historia Natural, actualmente Museo de las Ciencias.

Los autómatas abandonan los salones, y ocupan la calle donde se confunden con la farándula, los titiriteros y los recitadores y cantadores de aleluyas, coplas y pliegos de cordel. Por la primavera de 1791, el Caballero Pinetti muestra en el Coliseo del Príncipe, en Madrid, un espectáculo catóptrico (sic) de Máquinas Automáticas que, según pregona en un folleto, ha hecho admirar en la Europa y sus principales Cortes por sus ingeniosas operaciones físicas y matemáticas.

Se dan, habitualmente también, espectáculos de las nuevas maravillas e invenciones mecánico-luminosas en el teatro de la calle de la Sartén, los de la calle de la Cruz y Fúcar y el de la calle de la Montera, que anuncia en el otoño de 1788 un espectáculo de «Quatro piezas autómatas de maquinaria» y por fin, para que no nos falte un fino predecesor de la actual sensibilidad social de las damas de los «mercadillos» benéficos, se presentaba en los jardines del Retiro

${ }^{5}$ Alfredo Aracil, op. cit., p. 372. 
un «Gabinete del pobre» que representaba «el hogar de una familia humilde: una muchacha andrahoja, autómata, hilaba mientras mecía con movimientos muy naturales; al fondo se veía un matrimonio recién llegado de Cuba, representando ser los protectores de dicha familia pobre; el conjunto se completaba con una cama en la que reposaba el marido enfermo que hacía ademán de incorporarse y agradecer las gracias de los indianos ${ }^{6}$.

Máquinas y hombres caminan ya juntos y comienzan a repartirse el mundo con un sentimiento de horror, fascinación y miedo a los humanoides emblemáticos y enigmáticos. Emblemáticos porque «la misma historia de los autómatas resume la historia de la técnica, en sus tres fases esenciales: la mecánica- desde los orígenes de nuestra civilización hasta el siglo pasado—- la de la máquina a motor — desde mediados del XIX a mediados del nuestro-y la electrónica» ${ }^{7}$.

El renacimiento de lo maravilloso, la expresión irracional del sentimiento y las poéticas que priman la emoción sobre el pensamiento racional van a dar a luz los «monstruos» del Romanticismo en el XIx. Todavía anda por ahí la sombra medieval del Golem, la criatura de barro que cobraba vida al conjuro de la Cábala de los rabinos de Praga. Pero estos monstruos son solo los primos histéricos de los androides, criaturas literarias habitadas por un alma en guerra que, al menor descuido de sus creadores, les salía en forma de ángel o demonio por la nariz.

Los científicos, artistas y mecánicos de finales de siglo depositan en el cráneo de bronce del autómata un cerebro más o menos sofisticado, y ya tenemos al Robot, el autómata pensante. El robot no se angustia ni se avergüenza de su híbrida condición, no se afana en asaltar los cielos en busca de las respuestas que desazonan a sus modelos humanos. El robot suma, multiplica y nos trae el periódico.

Cuando a los robots de la Ciencia Ficción, Isaac Asimov les dota de un cerebro «positrónico», a imagen y semejanza del biológico, se ocupan también de filosofía y los problemas del mercado, y tratan de meterse en nuestra cama como objetos sexuales, usurpando actividades y dones que hacen renacer el viejo recelo del hombre por el «otro», forzando al mismo Asimov a implantarles las tres conocidas leyes, que son una especie de los mandamientos del buen robot.

De la incorporación de la electrónica, la informática y la biología al mundo de la robótica, van surgiendo nuevas criaturas de diversas cataduras; así, de la simbiosis del robot y el cuerpo biológico en un solo ser nace el cyborg, al que la medicina actual ha llegado hace tiempo con el progreso de la biomecánica,

${ }^{6}$ D.E.R.N., Guía histórica del parque de Madrid, 1879, pág. 28. Apud A. Aracil, p. 374.

${ }^{7}$ Mark Dery, Velocidad de escape: la cibercultura en el final del siglo, Madrid, Siruela, 1995, pág. 320. 
y con la incorporación de la informática la revolución del interfaz hombre-máquina se consuma y el espacio electrónico deja de ser un medio de información y se convierte en un medio de acción, y por tanto sus parámetros de funcionamiento no están limitados ni por la fisiología ni por el lugar, poniendo punto final a la filosofía y la fisiología humanas, resumido en el famoso slogan: «El cuerpo está obsoleto».

Un nuevo giro de tuerca tecnobiológico, y están junto a nosotros las familias de los «Clones» y los «replicantes», otra más, y ya en pleno siglo xxı, los «Morfos» y los «Neoformantes», envueltos en una sopa ideológica compuesta en partes variables por las teorías de McLuhan, las filosofías del caos y el conocimiento en lajas, las poéticas futuristas de Ballard y Sterling, junto a los escombros de ideologías políticas degradadas y cenitales. Todo envuelto en las plásticas Tardo-Pop y las performances de dudoso gusto multimedia, en las que los "poetas ejercen de científicos y éstos a su vez se embarcan en sus especulaciones no menos poéticas sobre las posibilidades posthumanas» ${ }^{8}$.

Pero es nuestro presente y recordamos con nostalgia el Autómata de Neuchâtel, que se movía en el entorno sencillo de la mecánica de la Revolución Industrial y no en las complejidades de lo sublime tecnológico y las apoteosis postevolutivas en las que todavía ayer Moravec declaraba «Somos objetos y la conciencia es el resultado de procesos completamente materiales» ${ }^{9}$.

Todas estas novísimas criaturas no nacen en una inclusa de la historia, sino formando parte de una larga familia cuyo árbol genealógico hemos rastreado hasta el gabinete del Siglo de las Luces, donde la abuela autómata, con sus gatos metálicos y la peluca ladeada sobre la cara de cobre dorado, con un gesto de duda metódica, teje los hilos de alambre de las vidas de las innumerables criaturas surgidas de su vagina de metal, lubrificada por jugosos aceites industriales, concebidas en perfectos jardines geométricos con el insaciable Casanova, o el pervertido abate Mical, o quizás el bueno de Descartes. Con su boca de fuelle todavía nos cuentan, en las noches de insomnio metafísico, las limpias historias de la Razón y de lo razonable.

\footnotetext{
${ }^{8}$ Hans Moravec, Mind children: the future if robot and Human Intelligence, Cambribge, Harvard University Press, 1988, pág. 6.

${ }^{9}$ Idem.
} 